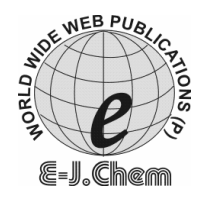

\title{
Extractive Spectrophotometric Method for Determination of Pioglitazone Hydrochloride in Raw Material and Tablets Using Ion-Pair Formation
}

\author{
MASSOUD AMANLOU*, MOHADESEH ZAREI-GHOBADI ${ }^{\S}$, \\ MOHAMMAD KAZEM ROFOUEI ${ }^{\S}$, SHAHROOZ SAREMI ${ }^{*}$ and \\ ABBAS KEBRIAEEZADEH ${ }^{\mathbb{I}}$ \\ Drug Design \& Development Research Center, \\ Tehran University of Medical Sciences, Tehran, Iran. \\ ${ }^{\S}$ Department of Chemistry, Tarbiat Moallem University, Tehran, Iran. \\ \# Department of Pharmaceutics, Faculty of Pharmacy, \\ Tehran University of Medical Sciences, Tehran, Iran. \\ ${ }^{I I}$ Departments of Pharmacology \& Toxicology, Faculty of Pharmacy, \\ Tehran University of Medical Sciences, Tehran, Iran. \\ amanlou@tums.ac.ir
}

Received 31 October 2009; Accepted 20 December 2009

\begin{abstract}
A simple, rapid and extractive spectrophotometric method was developed for the determination of pioglitazone hydrochloride in pure and pharmaceutical formulations. This method is based on the formation of yellow ion-pair complex between the basic nitrogen of the drug and bromocresol green (BCG) in phthalate buffer of $\mathrm{pH}$ 2.4. The formed complexes were extracted with chloroform and measured at $419 \mathrm{~nm}$. The analytical parameters and their effects on the proposed systems are investigated. Beer's law was obeyed in the range $2.5-14 \mu \mathrm{g} / \mathrm{mL}$ with correlation coefficient $\geq 0.995$. The proposed method has been applied successfully for the determination of drug in commercial tablets dosage forms. No significant interference was observed from the excipients commonly used as pharmaceutical aids with the assay procedure. The validity of the proposed method was established by parallel determination against HPLC method and there was no significant difference between these two methods.
\end{abstract}

Keywords: Pioglitazone, Extractive spectrophotometry, Bromocresol green, Ion-pair complex

\section{Introduction}

Pioglitazone hydrochloride (RS)-5-(4-[2-(5-ethylpyridin-2-yl)ethoxy]benzyl)thiazolidine2,4-dione hydrochloride (Figure 1) is an oral antidiabetic agent that has been shown to affect 
abnormal glucose and lipid metabolism associated with insulin resistance by enhancing insulin action on peripheral tissues in animal models ${ }^{1-5}$. Various method cited in literature for its determinations involve high performance liquid chromatography (HPLC) ${ }^{6-7}$, HPLC/MS ${ }^{8}, \quad$ HPLC/MS/MS ${ }^{9}$, TLC $^{10}$, HPLTC $^{11}$, capillary electrophoresis (CE) ${ }^{12}$, chemiluminescence $^{13}$, membrane selective electrode ${ }^{14}$ and potentiometry ${ }^{15}$.

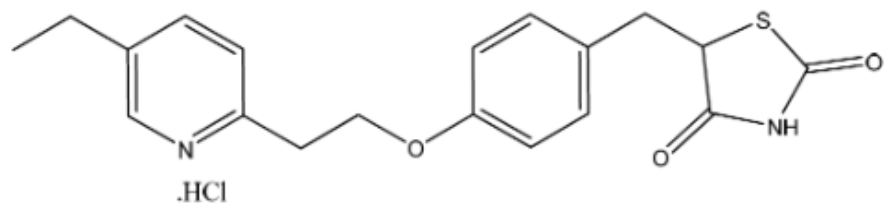

Figure 1. Chemical structure of pioglitazone hydrochloride.

Pioglitazone is not yet official in any pharmacopoeia and previously reported methods ${ }^{6-15}$ are costly and time consuming to be used in routine laboratories. We therefore, developed a simple and rapid spectrophotometric method with a one-step extraction procedure for determination of pioglitazone in pharmaceutical preparations. The application of this technique has been successfully applied for routine quality control analysis and compared to reported HPLC method.

Extractive spectrophotometric procedures are popular for their sensitivity in the assay of drugs. Therefore, ion-pair extractive spectrophotometry has received considerable attention for the quantitative determination of many pharmaceutical compounds ${ }^{16-19}$. So far, there has been no ion-pair extractive spectrophotometry method reported for an estimation of pioglitazone hydrochlordie.

\section{Experimental}

Pharmaceutical grade of pioglitazone hydrochloride was obtained from Osveh Pharmaceutical Co. (Tehran, Iran). All chemicals were of analytical-reagent grade from Merck (Germany). Doubly distilled water was used to prepare all solutions. Freshly prepared solutions were always employed. Standard buffer solution ( $\mathrm{pH} 1-5)$ was prepared by diluting $50 \mathrm{~mL}$ of $0.2 \mathrm{M}$ potassium phthalate and suitable quantity of $0.2 \mathrm{M} \mathrm{HCl}$ and diluting to $200 \mathrm{~mL}$ with distilled water. Bromocresol green solution $\left(B C G, 1 \times 10^{-4} \mathrm{M}\right.$ ), was prepared in distilled water. Tablets containing 15, 30, $45 \mathrm{mg}$ active materials were supplied from local Pharmacy.

\section{Apparatus}

A Shimadzu UV-160A, UV-VIS spectrophotometer (Japan) with $1 \mathrm{~cm}$ quartz cells was used for all absorbance measurements. The $\mathrm{pH}$ value of all buffers was adjusted using a Metrohm $692 \mathrm{pH}$ meter.

\section{Methodology}

\section{Standard solution of the drug}

A stock standard solution of pioglitazone hydrochloride $\left(1 \times 10^{-4} \mathrm{M}\right)$ was prepared by dissolving pioglitazone hydrochloride in minimum quantity $\mathrm{HCl} 0.1 \mathrm{~N}$ and was made up to the mark with distilled water. Working standard solutions were prepared by suitable dilution of the stock standard solution with water.

\section{Recommended procedure}

Into a series of $100 \mathrm{~mL}$ separating funnels, $10 \mathrm{~mL}$ of buffer solution of $\mathrm{pH} 2.4$ and $20 \mathrm{~mL}$ of BCG were placed. $3 \mathrm{~mL}$ of standard drug solution was added to each funnel and mixed well. 
The funnels were shaken vigorously with $10 \mathrm{~mL}$ chloroform for $2 \mathrm{~min}$ and then allowed to stand for clear separation of the two phases. The separated organic phase dried over anhydrous sodium sulfate and then was transferred to a $10 \mathrm{~mL}$ volumetric flask. Then the combined extract was made up to the mark with chloroform and mixed well. The absorbance of the organic phase was measured at $419 \mathrm{~nm}$ against a reagent blank similarly prepared. The standard calibration curve was prepared to calculate the amount of the analyte drug in unknown samples.

\section{Sample preparation}

Ten tablets were weighed and ground to a fine powder using a pestle and mortar. The average weight of one tablet was calculated. An accurately weighed portion of the powder equivalent to 1 tablet was transferred into a $100 \mathrm{~mL}$ volumetric flask, made up to the mark with water, shaken well and filtered through an ordinary filter paper.

\section{Results and Discussion}

Spectral characteristics

Absorption spectra of the yellow color pioglitazone-BCG ion-pair complex is shown in Figure 2 with a maximum absorbance at $419 \mathrm{~nm}$. The colorless blanks have practically negligible absorbance.

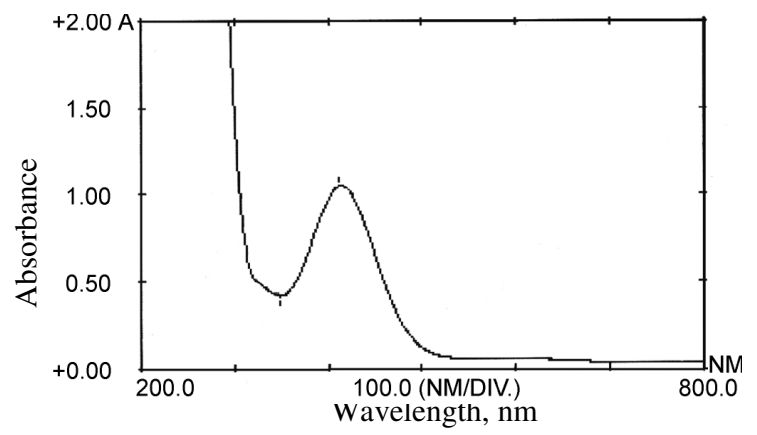

Figure 2. Absorption spectra of pioglitazone-BCG ion-pair complex in chloroform.

Reaction mechanism

Anionic dyes such as BCG forms ion-pair complex with the positively charged drugs. The drug-dye stoichiometric ratios as calculated by the continuous variation and mole-ratio methods were found to be 1:1. Each drug-dye complex, with two oppositely charged ions, behaves as a single unit held together by an electrostatic force of attraction.

Optimization of variables and method development

A number of preliminary experiments established optimum conditions necessary for rapid and quantitative formation of colored ion-pair complex to achieve the maximum stability and sensitivity. Optimum condition was fixed by varying one parameter at a time while keeping other parameters constant and observing its effect on the absorbance at $419 \mathrm{~nm}$.

\section{Effect of $p H$}

The influence of $\mathrm{pH}$ of buffer solution on the development and stability of the color using different buffer systems such as phthalate, phosphate and acetate buffers were tested in this study. Potassium hydrogen phthalate-HCl buffer was the buffer of choice, which did not interfere and gave the highest sensitivity for complex formation and extraction. Different $\mathrm{pH}(1-5)$ was tested and the absorbance reading of the pioglitazone-BCG ion-pair was examined (Figure 3). The maximum 
color intensity was observed in the $\mathrm{pH}$ range of 2-3 (Figure 3) and therefore $10 \mathrm{~mL}$ of pH 2.4 buffer solution, where maximum absorbance were achieved, was used throughout the experiment.

\section{Selecting of the extracting solvents}

The effect of the extracting solvent on the ion-pair complex was examined. Chloroform was preferred to other solvents (carbon tetrachloride, dichloromethane and ether) because of its slightly higher efficiency on color intensity, selective extraction of the complex from the aqueous phase and obtained highest absorbance.

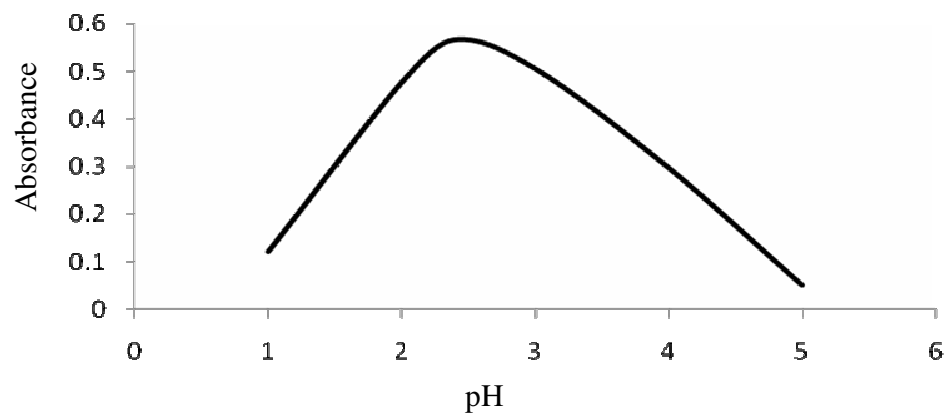

Figure 3. Effect of $\mathrm{pH}$ of buffer solution on the absorbance of pioglitazone-BCG ion-pair complex.

\section{Composition of ion-pair complexes}

The composition of the ion-pair complex was established by Job's method of continuous variations using variable dye and pioglitazone hydrochloride concentrations. The results indicated that 1:1 (drug:dye) ion-pair is formed through the electrostatic attraction between the positive protonated drug and the anion of dye (Figure 4). In addition, the mole-ratio method showed the formation of 1:5 ion-pair. Shape of the resulting curve indicates that the ion-pairs are labile (Figure 5). Consequently, a large excess of reagent must always be used to enhance the formation of the complex. A volume of $20 \mathrm{~mL}$ of BCG solution $\left(1 \times 10^{-4} \mathrm{M}\right)$ was found to be optimal for complete complexation and extraction.

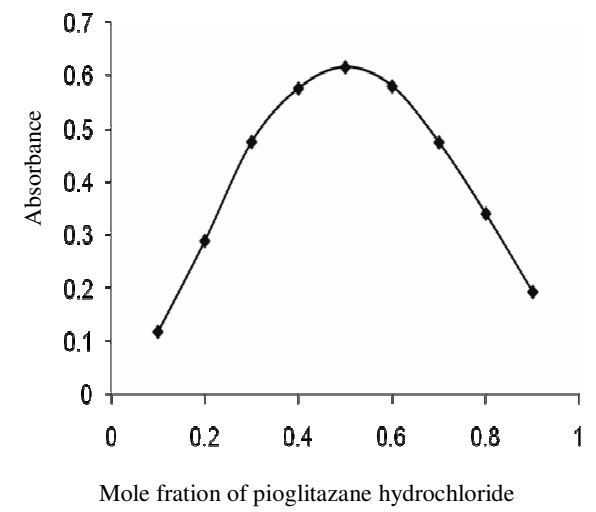

Figure 4. Job's method of continues variation plot for ion-pair complex of pioglitazone-BCG in chloroform at $419 \mathrm{~nm}$.

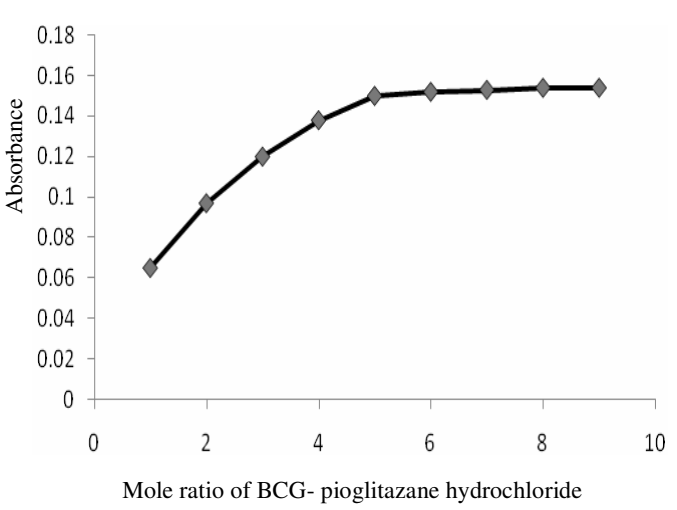

Figure 5. Mole-ratio method plot of pioglitazone-BCG ion-pair complex. 


\section{Analytical Data}

Under the optimized experimental condition, calibration curve was constructed by plotting the absorbance at $\lambda_{\max }$ against the concentration of pioglitazone hydrochloride. Beer's law was obeyed in the concentration range $2.5-14 \mu \mathrm{g} / \mathrm{mL}$. Regression analysis of the Beer's law plots at $\lambda_{\max }$ reveals a good correlation $\left(\mathrm{R}^{2}=0.995\right)$. The graph show negligible intercept and were described by the regression equation, $y=0.018 x+0.0007$ (where $y$ is the absorbance of $1 \mathrm{~cm}$ layer, 0.018 is the slope, 0.0007 is the intercept and $\mathrm{X}$ is the concentration of the measured solution in $\mu \mathrm{g} / \mathrm{mL}$ ) obtained by the least-squares method. The high molar absorptivities of the resulting colored complexes indicate the high sensitivity of the methods.

\section{Method validation}

Samples of pure pioglitazone hydrochloride at four different concentrations were prepared and tested using the proposed procedures in tree replicates. The complete set of validation assays was performed. The results obtained are given in Table 1. The accuracy of the method is indicated by the good recovery $(98.83-98.91 \%)$ and the precision is supported by the low relative standard deviation $(<1.31 \%)$.

Table 1. Evaluation of accuracy and precision for the proposed method.

\begin{tabular}{ccccc}
\hline $\begin{array}{c}\text { Amount } \\
\text { taken, } \mu \mathrm{g} / \mathrm{mL}\end{array}$ & $\begin{array}{c}\text { Amount found, } \\
\mu \mathrm{g} / \mathrm{mL}\end{array}$ & Recovery, \% & $\mathrm{RSD}, \%^{\mathrm{a}}$ & $\mathrm{RE}, \%$ \\
\hline 6 & 5.93 & 98.83 & 1 & -1.3 \\
9 & 8.85 & 98.44 & 1.3 & -1.6 \\
12 & 11.87 & 98.91 & 0.67 & -1.1 \\
\hline \multicolumn{5}{c}{ Average of tree determination }
\end{tabular}

\section{Tablets analysis}

The proposed method was successfully applied to the determination of pioglitazone in commercial tablets. The applicability of the proposed method for the assay pioglitazone in formulations was examined by analyzing various formulations and the results are tabulated in Table 2. Satisfactory results were obtained and were in a good agreement with the label claims for different batches. The average percent recoveries obtained were quantitative (97-97.88\%), indicating good accuracy of method.

Table 2. Determination of pioglitazone in different tablet dosage form using developed method.

\begin{tabular}{|c|c|c|c|c|c|}
\hline Drug trade name & $\begin{array}{l}\text { Tablets label } \\
\text { claim, mg }\end{array}$ & $\begin{array}{c}\text { Amount } \\
\text { taken, } \mu \mathrm{g} / \mathrm{mL}\end{array}$ & Recovery, \% & $\mathrm{RSD}, \%^{\mathrm{a}}$ & RE, \% \\
\hline \multirow{3}{*}{ Glutazone } & 15 & 9 & 97.22 & 2.1 & -2.71 \\
\hline & 30 & 9 & 97.00 & 2.5 & -2.58 \\
\hline & 45 & 9 & 97.77 & 1.6 & -2.32 \\
\hline \multirow{3}{*}{ Pitose } & 15 & 9 & 97.33 & 1.2 & -2.71 \\
\hline & 30 & 9 & 97.53 & 1.4 & -3.02 \\
\hline & 45 & 9 & 97.88 & 1.3 & -2.13 \\
\hline
\end{tabular}

The reliability and validity of the proposed method was established by parallel determination against HPLC method using previously reported method ${ }^{7}$. The results were accurate and reproducible and there was no significant difference between these two methods (Table 4). The results were tested by student's $t$-test and no significant difference was seen between these two methods $(\mathrm{P}<0.05)$. 
Table 3. Determination of pioglitazone in tablets using proposed and HPLC methods.

\begin{tabular}{lcccc}
\hline $\begin{array}{c}\text { Drug trade } \\
\text { name }\end{array}$ & $\begin{array}{c}\text { Tablets label } \\
\text { claim, } \mathrm{mg}\end{array}$ & $\begin{array}{c}\text { Amount taken } \\
\mu \mathrm{g} / \mathrm{mL}\end{array}$ & $\begin{array}{c}\text { Amount found } \\
\text { (proposed method) }\end{array}$ & $\begin{array}{c}\text { Amount found } \\
\text { (HPLC method) }\end{array}$ \\
\hline Glutazone & 30 & 9 & $29.83 \pm 0.34$ & $29.37 \pm 0.12$ \\
Pitose & 30 & 9 & $31.09 \pm 0.77$ & $29.82 \pm 0.16$ \\
\hline
\end{tabular}

The results of analysis of the commercial tablets and the recovery study of drug suggested that there is no interference in the analysis from the commonly used additives and excipients in pharmaceutical dosage forms of pioglitazone such as calcium phosphate, magnesium stearate, lactose, cellulose, povidone, and silicon dioxide. The maximum color development of pioglitazone-BCG ion-pair complex formation completed immediately after all reagents were added. No heating or standing was needed.

The present method is not time-consuming procedure such as the standard addition method and there is no need for any expensive equipment. This method does not involve procedural steps; take more operator time and expertise like HPLC and other similar methods. On the other hand, in terms of simplicity, rapidity, sensitivity and expense, this method could be considered superior in comparison with the previously reported methods. The proposed method is simple and rapid with reasonable precision and accuracy when compared to other reported methods. The wide applicability of the described procedure for routine quality control is well established by the assay of pioglitazone in pure form, as well as in pharmaceutical preparations.

\section{Conclusion}

In the present study, an ion-pair formation method is described. This method is simple, rapid, accurate and not time-consuming techniques such as GC, HPLC and etc. These advantages encouraged the application of the proposed method in routine quality control of pioglitazone in raw material samples and pharmaceutical preparations in pharmaceutical laboratories.

\section{Acknowledgments}

This project was supported by grants from the Research Council of Tehran University of Medical Sciences and INSF (Iran National Science Foundation) and Osveh Pharmaceutical Company.

\section{References}

1. Sohda T, Momose Y, Meguro K, Kawamatsu Y, Sugiyama Y and Ikeda H, Arzneim Forsch., 1990, 40, 37.

2. Hofmann C A, Edwards C W, Hillman R M and Colca J R, Endocrinology, 1992, 130, 735.

3. Kletzien R F, Foellmi L A, Harris P K W, Wyse B M and Clarke S D, Mol Pharmacol., 1992, 42, 558.

4. Sohda T, Mizuno K, Momose Y, Ikeda H, Fujita T and Meguro K, J Med Chem., 1992, 35, 2617.

5. Kobayashi M, Iwanishi M, Egawa K and Shigeta Y, Diabetes, 1992, 41, 476.

6. Sripalakit P, Neamhom P and Saraphanchotiwitthaya A, J Chromatogr B, 2006, 843, 164.

7. Souri E, Jalalizadeh H and Saremi S, J Chromatogr Sci., 2008, 46, 809.

8. Xue Y.-J, Turner K C, Meeker J B, Pursley J, Arnold M and Unger S, J Chromatogr $B, 2003,795,215$.

9. John Lin Z, Ji W, Desai-Krieger D and Shum L, J Pharm Biomed Anal., 2003, 33, 101. 
10. Bhushan R, Gupta D and Jain A, J Planar Chromatogr., 2006, 19, 288.

11. Jiladia M A, Pandya S S and Viidyasagar G, Asian J Res Chem., 2009, 2, 207.

12. Radhakrishna T, Sreenivas Rao D and Om Reddy G, J Pharm Biomed Anal., 2002, 29, 593.

13. Al-Arfaj N A, Al-Abdulkareem E A and Aly F A, Anal Sci., 2009, 25, 401.

14. El-Ghobashy M R, Yehia A M and Mostafa A A, Anal Lett., 2009, 42, 123.

15. Mostafa A E G and Al- Majed A, J Pharm Biomed Anal., 2008, 48, 57.

16. Amanlou M, Khosravian P, Souri E, Dadrass O G, Dinarvand R, Alimorad M M and Akbari H, Bull Korean Chem Soc., 2006, 28, 183.

17. Amanlou M, Nazlou MH, Azizian H, Souri E and Farsam H, Anal Lett., 2007, 40, 3267.

18. Amanlou M, Keivani S, Sadri B, Gorban-Dadras O and Souri E, Research in Pharmaceutical Sciences, 2009, 4, 11.

19. Ganesh M, Thangabalan B, Patil R, Ganguly S and Sivakumar T, E Journal of Chemistry, 2008, 5, 593. 


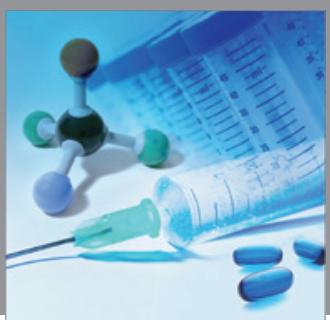

International Journal of

Medicinal Chemistry

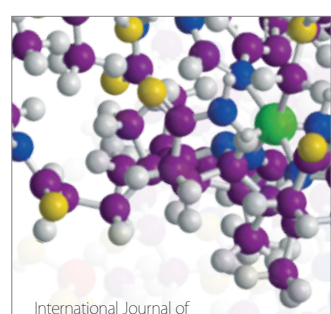

Carbohydrate Chemistry

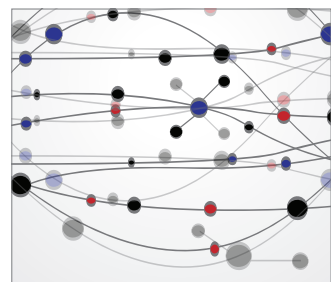

The Scientific World Journal
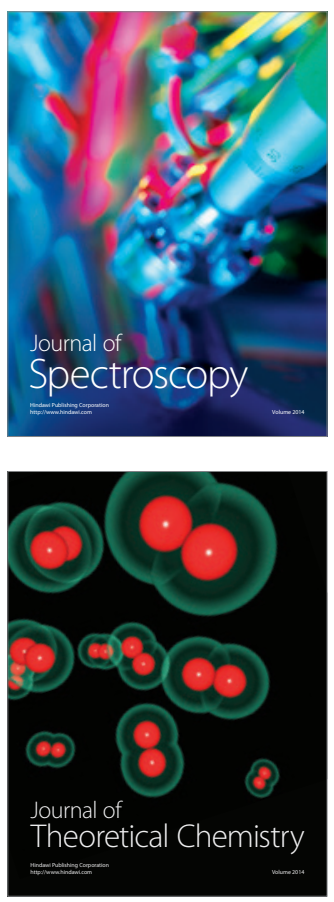
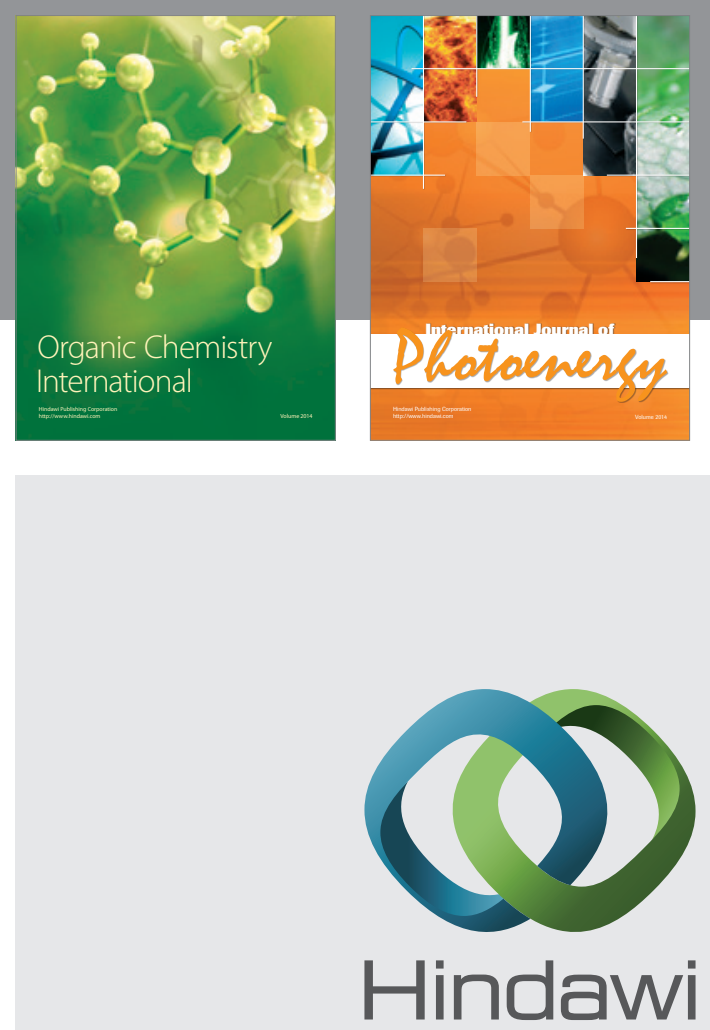

Submit your manuscripts at

http://www.hindawi.com
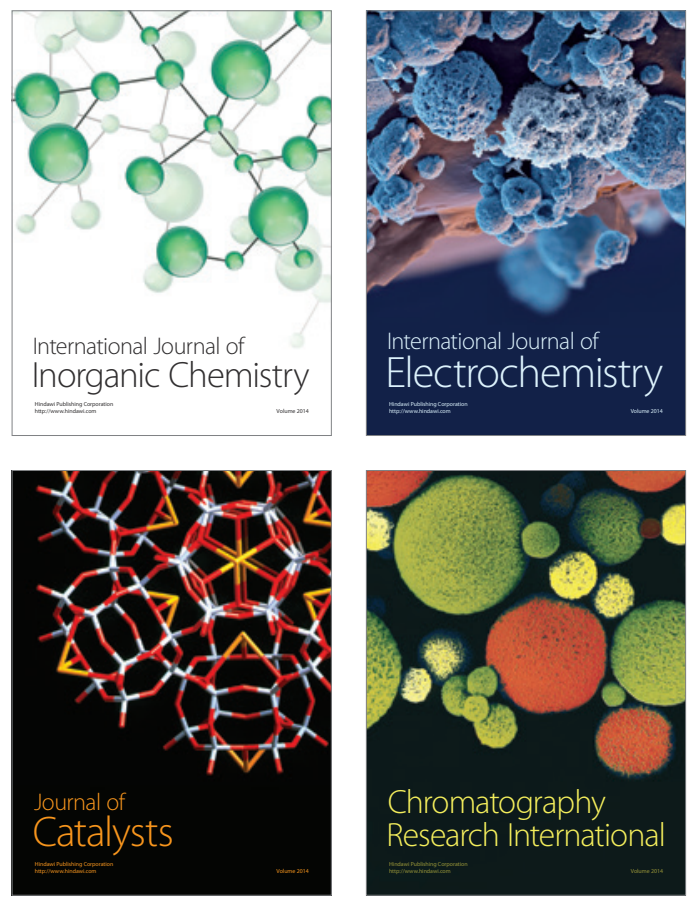
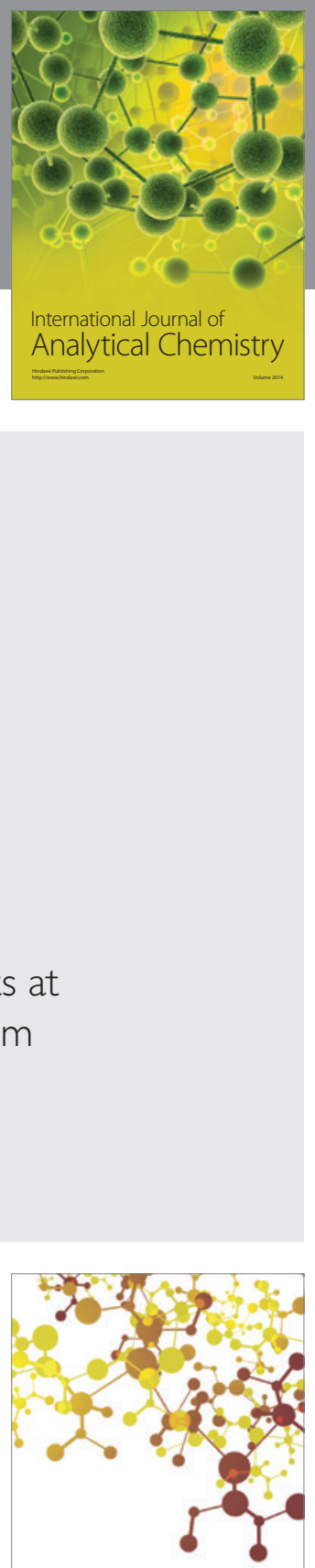

Journal of

Applied Chemistry
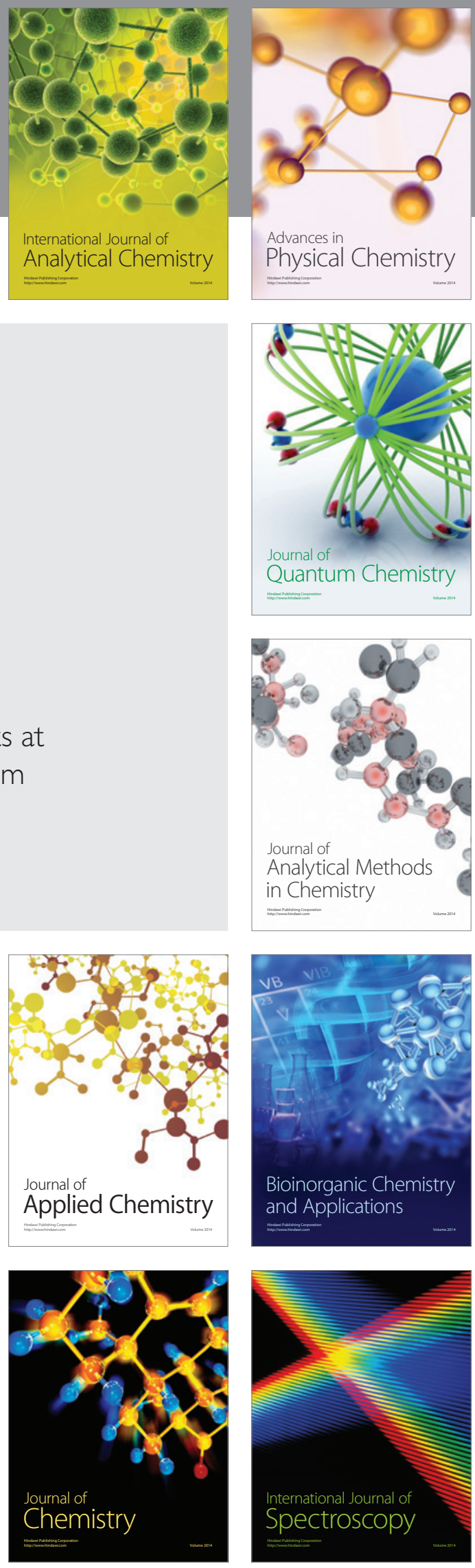